Dan-Xia Li*, Hai-Jun Wang, Zhen-Li Yan and Chao-Jun Du

\title{
The crystal structure of 6-amino-
}

\section{5-carboxypyridin-1-ium pentaiodide monohydrate $\mathrm{C}_{6} \mathrm{H}_{9} \mathrm{I}_{5} \mathrm{~N}_{2} \mathrm{O}_{3}$}

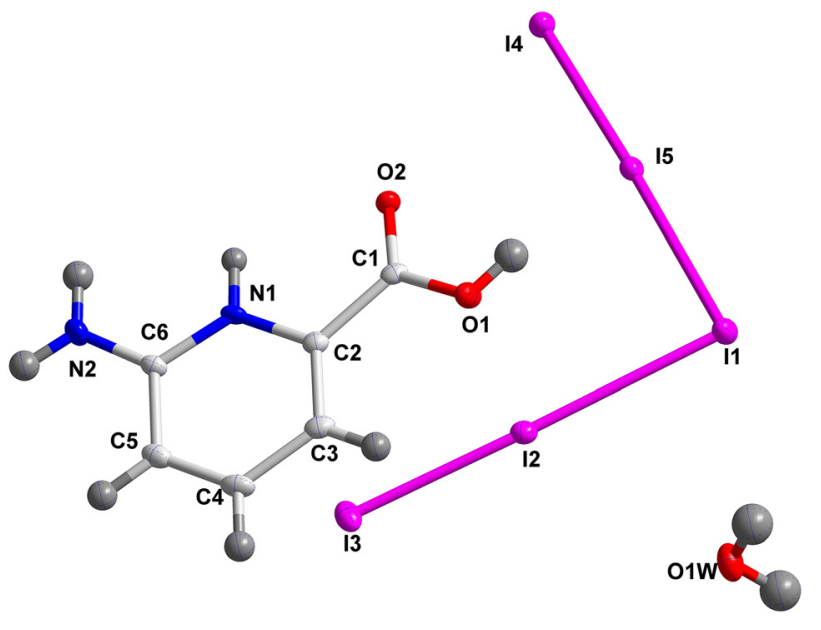

https://doi.org/10.1515/ncrs-2021-0422

Received October 27, 2021; accepted December 9, 2021;

published online January 4, 2022

\begin{abstract}
$\mathrm{C}_{6} \mathrm{H}_{9} \mathrm{I}_{5} \mathrm{~N}_{2} \mathrm{O}_{3}$, triclinic, $P \overline{1}$ (no. 2), $a=7.4851(5) \AA$, $b=9.6056(6) \AA, c=12.4084(7) \AA, \alpha=109.119(3)^{\circ}$, $\beta=99.341(3)^{\circ}, \gamma=92.334(3)^{\circ}, V=827.53(9) \AA^{3}, Z=2$, $R_{g t}(F)=0.0234, w R_{r e f}\left(F^{2}\right)=0.0449, T=150.0 \mathrm{~K}$.
\end{abstract}

CCDC no.: 2127394

The molecular structure is shown in the figure. Table 1 contains crystallographic data and Table 2 contains the list of the atoms including atomic coordinates and displacement parameters.

*Corresponding author: Dan-Xia Li, Zhang Zhongjing College of Chinese Medicine, Nanyang Institute of Technology, Nanyang, Henan, 473000, P. R. China, E-mail: 781488117@qq.com

Hai-Jun Wang, Agriculture Engineering Department, Nanyang Vocational College of Agriculture, Nanyang, Henan, 473000, P. R. China Zhen-Li Yan, State key Laboratory of Motor Vehicle Biofuel Technology, Nanyang, Henan, 473000, P. R. China

Chao-Jun Du, Nanyang Research Institute of Zhengzhou University, Nanyang Institute of Technology, Nanyang, Henan, 473000, P. R. China. https://orcid.org/0000-0002-4767-7057
Table 1: Data collection and handling.

\begin{tabular}{ll}
\hline Crystal: & Red block \\
Size: & $0.20 \times 0.15 \times 0.10 \mathrm{~mm}$ \\
Wavelength: & Mo $K \alpha$ radiation $(0.71073 \AA)$ \\
$\mu:$ & $9.39 \mathrm{~mm}^{-1}$ \\
Diffractometer, scan mode: & BRUKER APEX-II, $\varphi$ and $\omega$ \\
$\theta_{\text {max }}$, completeness: & $26.4^{\circ},>99 \%$ \\
$N(h k l)_{\text {measured }}, N(h k l)_{\text {unique }}, R_{\text {int }}:$ & $17,263,3386,0.045$ \\
Criterion for $l_{\text {obs }}, N(h k l)_{\text {gt }}:$ & $I_{\text {obs }}>2 \sigma\left(I_{\text {obs }}\right), 2864$ \\
$N(\text { param })_{\text {refined }}:$ & 149 \\
Programs: & Bruker [1], OLEX2 [2], SHELX [3, 4]
\end{tabular}

\section{Source of material}

An amount of $1.38 \mathrm{~g}$ of 6-aminopyridine-2-carboxylic acid (10 mmol) was dissolved in $10 \mathrm{~mL} 45 \%$ hydroiodic acid, then filtered. Many red crystals were harvested after about 10 days, yield $74 \%$ (based on 6-aminopyridine-2-carboxylic acid).

\section{Experimental details}

The structure was solved by direct methods with the SHELXS program. All $\mathrm{H}$-atoms from $\mathrm{C}$ and $\mathrm{N}$ atoms were positioned with idealized geometry $\left(U_{\text {iso }}(\mathrm{H})=1.2 U_{\text {eq }}(\mathrm{C})\right.$ and $(\mathrm{N}))$ using a riding model with $\mathrm{C}-\mathrm{H}=0.95 \AA$ and $\mathrm{N}-\mathrm{H}=0.88 \AA$. The $\mathrm{H}$-atoms for $\mathrm{O}$ and $\mathrm{O} 1 \mathrm{~W}$ were refined with the distance of $01-\mathrm{H} 1 \mathrm{~A}=0.84,01-\mathrm{H} 1 \mathrm{WA}=$ O1-H1WB $=0.87 \AA$ with $U_{\text {iso }}(\mathrm{H})=1.5 U_{\text {eq }}(0)$, respectively.

\section{Comment}

Many pyridinium-based polyiodides have been reported, for example, 2-amino-pyridin-1-ium triiodide [5, 6] and bis((4-aminopyridin-1-ium) iodide triiodide. But only a few pyridinium-based pentaiodides have been published, such as aminopyridinium pentaiodide [7], isoquinolinium pentaiodide [8], nevirapinium pentaiodide [9], $N$-(6-methyl2-pyridyl)mesitylenesulfonamide pentaiodide [10], and 
Table 2: Fractional atomic coordinates and isotropic or equivalent isotropic displacement parameters $\left(\AA^{2}\right)$.

\begin{tabular}{lrrrr}
\hline Atom & $\boldsymbol{x}$ & $\boldsymbol{y}$ & $\boldsymbol{z}$ & \multicolumn{1}{c}{$\boldsymbol{U}_{\text {iso }}{ }^{*} \boldsymbol{U}_{\text {eq }}$} \\
\hline C1 & $0.9540(6)$ & $0.2526(5)$ & $0.6136(4)$ & $0.0204(10)$ \\
C2 & $0.8744(6)$ & $0.2678(5)$ & $0.5012(4)$ & $0.0209(10)$ \\
C3 & $0.8110(6)$ & $0.3904(5)$ & $0.4862(4)$ & $0.0257(11)$ \\
H3 & 0.816407 & 0.478628 & 0.550662 & $0.031^{*}$ \\
C4 & $0.7357(6)$ & $0.3856(6)$ & $0.3719(4)$ & $0.0279(11)$ \\
H4 & 0.687965 & 0.470450 & 0.359699 & $0.033^{*}$ \\
C5 & $0.7322(6)$ & $0.2592(6)$ & $0.2800(4)$ & $0.0269(11)$ \\
H5 & 0.682366 & 0.256349 & 0.203720 & $0.032^{*}$ \\
C6 & $0.8028(6)$ & $0.1314(5)$ & $0.2977(4)$ & $0.0208(10)$ \\
I1 & $0.62729(5)$ & $0.31666(4)$ & $0.96864(3)$ & $0.02959(9)$ \\
I2 & $0.48900(4)$ & $0.25468(3)$ & $0.69938(2)$ & $0.02325(8)$ \\
I3 & $0.36535(4)$ & $0.18894(4)$ & $0.46452(3)$ & $0.03150(9)$ \\
I4 & $0.80776(5)$ & $-0.30113(4)$ & $0.81772(3)$ & $0.03111(9)$ \\
I5 & $0.72338(4)$ & $-0.00810(3)$ & $0.89310(2)$ & $0.02435(8)$ \\
N1 & $0.8668(5)$ & $0.1409(4)$ & $0.4078(3)$ & $0.0189(8)$ \\
H1 & 0.905890 & 0.061554 & 0.420587 & $0.023^{*}$ \\
N2 & $0.8079(5)$ & $0.0076(4)$ & $0.2119(3)$ & $0.0277(9)$ \\
H2A & 0.853126 & -0.068723 & 0.226765 & $0.033^{*}$ \\
H2B & 0.765963 & 0.001213 & 0.139807 & $0.033^{*}$ \\
O1 & $0.9811(5)$ & $0.3782(3)$ & $0.7009(3)$ & $0.0275(8)$ \\
H1A & 1.020862 & 0.362390 & 0.762739 & $0.041^{*}$ \\
O2 & $0.9927(4)$ & $0.1336(3)$ & $0.6218(2)$ & $0.0223(7)$ \\
01W & $0.0920(6)$ & $0.3149(4)$ & $0.8878(3)$ & $0.0399(9)$ \\
H1WA & 0.199111 & 0.349720 & 0.930224 & $0.060^{*}$ \\
H1WB & 0.017030 & 0.342507 & 0.935769 & $0.060^{*}$ \\
\hline & & & &
\end{tabular}

3-[5-(pyridin-3-yl)-1,2,4-thiadiazol-3-yl]pyridinium pentaiodide [11].

The title compound, with the formula of $\mathrm{C}_{6} \mathrm{H}_{9} \mathrm{I}_{5} \mathrm{~N}_{2} \mathrm{O}_{3}$, crystalizes in triclinic, $P-1$ (no. 2). The asymmetric unit is made of one 6-amino-5-carboxypyridin-1-ium cation, one pentaiodide anion and one water molecule. In the 6-amino5-carboxypyridin-1-ium cation, the $\mathrm{N}$ atom from of the pyridine ring is protonated and both the amino and carboxyl groups are neutral. The distances of I4-I5 and I2-I3 are 2.794 and $2.760 \AA$, respectively, rather shorter than the distances of I1-I5 (3.101 $\AA$ ) and I1-I2 (3.181 ̊̊). The structure features an organic moiety consisting of two water molecules and two cations to form the dimers, which are generated by the hydrogen bonds $\mathrm{N} 1-\mathrm{H} 1 \cdots \mathrm{O} 2, \mathrm{~N} 2-\mathrm{H} 2 \mathrm{~A} \cdots \mathrm{O} 2$, and 01-H1A...01W. The anions and the cations are connected by van der Waals interactions to form layers in the $b c$ plane.
Author contributions: All the authors have accepted responsibility for the entire content of this submitted manuscript and approved submission.

Research funding: None declared.

Conflict of interest statement: The authors declare no conflicts of interest regarding this article.

\section{References}

1. Bruker. SAINT v8.37A; Bruker AXS Inc: Madison, Wisconsin, USA, 2015.

2. Bourhis L. J., Dolomanov O. V., Gildea R. J., Howard J. A. K., Puschmann $\mathrm{H}$. The anatomy of a comprehensive constrained, restrained refinement program for the modern computing environment-Olex2 dissected. Acta Crystallogr. 2015, A71, 59-75.

3. Sheldrick G. M. Crystal structure refinement with SHELXL. Acta Crystallogr. 2015, C71, 3-8.

4. Sheldrick G. Using phases to determine the space group. Acta Crystallogr. 2018, A74, a353.

5. Reiss G. J., Leske P. B. 2-Amino-pyridin-1-ium triiodide. Acta Crystallogr. 2013, E69, 01060-01061.

6. Reiss G. J., Leske P. B. The twinned crystal structure of bis(4-aminopyridin-1-ium) iodide triiodide, $\mathrm{C}_{20} \mathrm{H}_{28} \mathrm{I}_{8} \mathrm{~N}_{8}$. Z. Kristallogr. N. Cryst. Struct. 2014, 229, 452-454.

7. Buikin P. A., Ilyukhin A. B., Baranchikov A. E., Yorov K. E., Kotov V. Y. The relationship between the crystal structure and optical properties for isomeric aminopyridinium iodobismuthates. Mendeleev Commun. 2018, 28, 490-492.

8. Wu Y., Shao M., Feng Z., Gu X., Hong Y., Cui Q., Ren L., Wang S. Synthesis of iodine-substituted quinolines, quinolinium salts, and isoquinolinium salts via a three-component tandem reaction of aryl azides, propargylic alcohols, and iodine. Asian J. Org. Chem. 2017, 66, 76-82.

9. Kryukova M. A., Sapegin A. V., Novikov A. S., Krasavin M., Ivanov D. M. Non-covalent interactions observed in nevirapinium pentaiodide hydrate which include the rare $\mathrm{I}_{4}-\mathrm{I}^{-} \ldots \mathrm{O}=\mathrm{C}$ halogen bonding. Z. Kristallogr. Cryst. Mater. 2019, 234, 101-108.

10. Pan F., Englert U. $N$-(6-methyl-2-pyridyl)mesitylenesulfonamide: an efficient template for polyiodides. Cryst. Growth Des. 2014, 14, 1057-1066.

11. Aragoni M. C., Arca M., Caltagirone C., Castellano C., Demartin F., Garau A., Isaia F., Lippolis V., Montis R., Pintus A. Cationic and anionic 1D chains based on $\mathrm{NH}^{+} \ldots \mathrm{N}$ charge-assisted hydrogen bonds in bipyridyl derivatives and polyiodides. CrystEngComm 2012, 14, 5809-5823. 